\title{
The promoting effect of cesium on structure and morphology of silver catalysts
}

\author{
MARTA C. N. A. CARVAlho ${ }^{1}$, CARlos A. PEREZ ${ }^{1}$, RENATA A. Simão ${ }^{2}$ \\ FABIO B. PASSOS ${ }^{3}$ and MARTIN SCHMAL ${ }^{1}$ \\ ${ }^{1}$ Universidade Federal do Rio de Janeiro, NUCAT/PEQ/COPPE, Cx. Postal 68502, 21945-970 Rio de Janeiro, RJ, Brasil \\ ${ }^{2}$ Universidade Federal do Rio de Janeiro, PEMM/COPPE, 21945-970 Rio de Janeiro, RJ, Brasil \\ ${ }^{3}$ Universidade Federal Fluminense, Departamento de Engenharia Química, 24210-240 Niterói, RJ, Brasil
}

Manuscript received on May 25, 2003; accepted for publication on October 27, 2003

contributed by MARTIN SCHMAL*

\begin{abstract}
Silver supported catalysts on alpha-alumina were prepared and characterized by Brunauer-Emmet-Teller equations, scanning electronic microscopy, X-ray diffraction and atomic force microscopy techniques. Results show that these are powerful techniques for the determination of texture, morphology and surface properties. It has been shown that the addition of $\mathrm{Cs}$ in the $\mathrm{Ag} / \mathrm{Al}_{2} \mathrm{O}_{3}$ catalyst increased the dispersion of silver with the formation of small silver particles over a thin silver film already formed over the alumina support. It is important to stress that atomic force microscopy measurements are significant to observe the film and the dispersion of Ag and, on the contrary, X-ray photoelectronic spectroscopy did not, however, it allows to the conclusion that undistinguishable silver, either as metallic or oxidation state, are present at the surface. X-ray diffraction results confirm predominantly metallic silver.
\end{abstract}

Key words: silver, cesium, catalyst, AFM, XPS.

\section{INTRODUCTION}

Ethylene oxide is a valuable compound due to its versatility as chemical intermediate in many industrial processes. Its production is a great proportion business, where millions of tons are produced every year, corresponding to one of the world greatest industrial capacity (Riassian et al. 1977). Most of the produced ethylene oxide is converted to ethylene glycol, which is used as antifreeze or to make polyester fibers. Commercially, the ethylene oxide is produced exclusively via partial oxidation of ethylene on catalysts containing silver as main component. Ethylene oxide has been produced for more

\footnotetext{
* Member of Academia Brasileira de Ciências

Correspondence to: Martin Schmal

E-mail: schmal@peq.coppe.ufrj.br
}

than fifty years by oxidation of ethylene over silver supported alumina catalyst.

The main interest of the researches was to increase the selectivity. During the thirties, the selectivity was around $40 \%$. In the sixties, the selectivity progressively increased up to $68 \%$ by the introduction of moderator compounds, generally chlorine containing hydrocarbons in the reactant flow. More recently, significantly changes in the preparation method and the introduction of alkali promoters increased in more than $10 \%$ the selectivity to ethylene oxide. Nowadays, the commercial catalysts exhibit around $80 \%$ selectivity. Some authors (Young et al. 1990, Van Santen and Kuipers 1987, Minahan and Hoflund 1996, Bal'zhinimaev et al. 1998, Deng et al. 1992) related experimental selectivity above 
the stoichiometric limit of $85.7 \%$.

In this exciting domain of ethylene oxide production, the development of high technology was very important for the knowledge of the surface properties of the catalysts. The utilization of different supports, preparation methods and the introduction of promoters and moderators were improved. In the last 10 years great progress was achieved in the ethylene epoxidation studies, due to the modern development in surface science, which allowed to a better understanding of the reaction.

The effect of promoter addition to silver catalyst is not yet completely understood. Considering only the electronic effects, Cs should decrease the selectivity to ethylene oxide by electronic charge donation to the atomic oxygen (Serafin et al. 1998). Actually, with Cs addition on $\mathrm{Ag}$ (111) an increase of $\mathrm{CO}_{2}$ production by ethylene combustion and a decrease of $\mathrm{CO}_{2}$ associated to the ethylene oxide formation was observed. Grant and Lambert attributed these facts to an increase oxygen electronic density, which inhibits the opening of the epoxide ring and thus its decomposition (Grant and Lambert 1985). This conclusion was also sustained by other work (Tan et al. 1987). Campbell studied the same system on crystalline phase and suggested that Cs structure is more complex, observing the formation of $\mathrm{CsO}_{3}$ species, which can generate some electronic or geometric (Campbell 1986) effects. A recent report showed that Ag $(110)$ suffers a $(1 \times 2)$ reconstruction with Cs adsorption (Serafin et al. 1998), and that $\mathrm{Cs}$ increases the $\mathrm{CO}_{2}$ release by silver in the presence of oxygen. This later effect decreases the ethylene oxide combustion, inhibiting the additional $\mathrm{CO}_{2}$ formation. Authors explain that from the two opposite effects on the selectivity, the suppression of ethylene oxide oxidation prevails compared to the increase surface oxygen electronic density in the presence of $\mathrm{Cs}$, which enhances the ethylene oxide formation.

It turns out that Cs acts either by diminishing and stabilizing the $\mathrm{Ag}$ particles size, increasing the crystalline lattice defects, where probably the electrophilic oxygen is located (Grant and Lam- bert 1985), and on the other hand, may decrease the nucleophilic oxygen concentration (surface $\mathrm{Ag}_{2} \mathrm{O}$ ), which is responsible for the ethylene deep oxidation (Bukhtiyarov et al. 1994). Once the epoxidation rate remains stable (Goncharova et al. 1995) it can be suggested that the ratio of the amounts of regular and defective surface regions, claimed for ethylene epoxidation, remains constant or slightly increases. Therefore, Cs can generate substantial changes in the structure, such as decrease of $\mathrm{Ag}_{2} \mathrm{O}$ islands or increase (stabilization) of defective regions. However, excess of Cs may block the active surface sites and, thus, decrease the reaction rate in both directions.

The main reaction steps and the action of promoters and moderators on the reaction mechanism were explained in the absence of additional complex effects, such as, high pressure, high temperature, competing adsorptions and support material. However, novel "in situ" techniques became reliable, generating detailed information of the catalyst under operational conditions. The challenge of a new research is to correlate the electronic and structural data to the surface properties, using model systems, and taking into account the small variations of a real catalyst, which results in significant economic consequences. Recent reports are focusing the question concerning the nature of oxygen species participating in the ethylene oxidation reaction. However, there are still many open questions concerning the transition state.

The objective of this work is the study the morphological and structural changes of silver catalysts by the addition of cesium as promoter agent. Silver catalysts were prepared and promoted with Cs, using $\alpha$-alumina as support, which are characterized using X-ray diffraction (XRD) and surface analysis, such as spectroscopic techniques and microscopy.

\section{MATERIALS AND METHODS}

The catalysts were prepared by impregnation of Silver on $\alpha$-alumina support NORTON (N), using a silver lactate aqueous solution (Liu and Shen 1995). Sample containing cesium was obtained by 
co-impregnation, adding cesium hydroxide to silver solution. For the determination of silver content, previously silver was extracted by nitric acid and the amount was analyzed volumetrically, using the Volhard method (Kobal Júnior and Sartorio 1981). The determination of Cs content was obtained by atomic absorption measurements of the solution, after extraction of Cs with reflux in deionized water.

Specific area was obtained with $\mathrm{N}_{2}$ adsorption using the Brunauer-Emmet-Teller (BET) method (Brunauer et al. 1938) in ASAP 2000 Micromeritics equipment. The XRD analysis was obtained in RIGAKU X-ray diffraction equipment, with increasing scanning of $0.05^{\circ}$ step, between $0^{\circ}$ and $110^{\circ}$, and speed of 0.01 steps per 5 seconds.

The scanning electronic microscopy (SEM) analysis was obtained in JEOL, JSM 5300 equipment.

The X-ray photoelectronic spectroscopy (XPS) was obtained in a 1257 model Perkin Elmer spectrometer, using ( $\mathrm{Mg} \mathrm{K} \alpha \mathrm{h} v=1253.6 \mathrm{eV}$ ) radiation as exiting source. Samples were pretreated at $180^{\circ} \mathrm{C}$ in a pre-chamber, evacuated at $10^{-6}$ and then introduced in the UHV chamber under $10^{-10}$ Torr.

The atomic force microscopy (AFM) images were made by a TopoMetrix, Accurex II equipment at non contact mode, using silicon probe with dimensions of: $125 \mu \mathrm{m}$ of length, 23 to $38 \mu \mathrm{m}$ of width and 3 to $5 \mu \mathrm{m}$ of thickness. The samples were not pretreated.

\section{RESULTS AND DISCUSSION}

\section{Textural Analysis}

The BET results of specific surface area and porosity are presented in Table I. The surface area of the $\alpha$ alumina support is very low $\left(\sim 1 \mathrm{~m}^{2} / \mathrm{g}\right)$, with prevailing macropores. The pore volume and particle density were determined by using an analytical method in picnometer.

\section{Chemical Analysis}

The $\mathrm{Ag}$ contents on the $\mathrm{Ag} / \mathrm{N}$ and $\mathrm{AgCs} / \mathrm{N}$ samples were $15.7 \%$ and $15.2 \%$ (wt), respectively. Cs con-
TABLE I

Textural analysis of the catalysts.

\begin{tabular}{l|l}
\hline BET area & $0.32 \mathrm{~m}^{2} / \mathrm{g}$ \\
\hline Density & $3.76 \mathrm{~g} / \mathrm{cm}^{3}$ \\
\hline Micropore volume & $6.93 \mathrm{~cm}^{3} / \mathrm{g} \times 10^{-4}$ \\
\hline Macropore volume & $0.25 \mathrm{~cm}^{3} / \mathrm{g}$ \\
\hline $\begin{array}{c}\text { Micro/mesopore } \\
\text { average diameter }\end{array}$ & $61.8 \AA$ \\
\hline Porosity & $48.7 \%$ \\
\hline
\end{tabular}

tent was $211 \mathrm{ppm}$. These values are close to the nominal predicted values of $15 \%$ of silver and $200 \mathrm{ppm}$ of Cs. In addition the bulk $\mathrm{Ag} / \mathrm{Al}$ ratios are of the order of 0.090 and 0.085 , without and with Cs, respectively.

\section{X-ray Photoelectronic Spectroscopy (XPS)}

\section{Surface ANALYsis}

The XPS analysis, using an $\mathrm{Mg} \mathrm{K} \alpha$ radiation source, displayed the elements $\mathrm{Al}, \mathrm{O}, \mathrm{Ag}, \mathrm{Cs}, \mathrm{Si}$ and $\mathrm{Na}$ at the surface on all samples (Figure 1). Sodium and silicon were found on the commercial $\alpha$-alumina support (Minahan and Hoflund 1996). The surface ratios of $\mathrm{Si} / \mathrm{Al}$ and $\mathrm{Na} / \mathrm{Al}$ are displayed in Table II. It shows that the $\mathrm{Si} / \mathrm{Al}$ ratio at the surface of the catalyst did not change much compared to the support, while the $\mathrm{Na} / \mathrm{Al}$ ratio, not detected at the surface of the support, migrated at the surface of the silver catalyst, but very little in the presence of Cs.

Table II compares the surface and bulk Ag/Al and $\mathrm{Cs} / \mathrm{Al}$ atomic ratios. The results show that either most silver or cesium is concentrated at the surface, which is probably due to the low $\alpha$-alumina surface area $\left(<0.5 \mathrm{~m}^{2} / \mathrm{g}\right)$.

The $\mathrm{Ag} 3 \mathrm{~d}$ spectrum of $\mathrm{Ag} / \mathrm{N}$ and $\mathrm{Cs}, \mathrm{Ag} / \mathrm{N}$ catalysts are presented in Figure 2. The bond energy values of $\mathrm{Ag} 3 \mathrm{~d}$ of the catalysts and the standard compounds (Wagner et al. 1979) are listed in Table III. It shows metallic $\mathrm{Ag}^{0}, \mathrm{Ag}_{2} \mathrm{O}$ and $\mathrm{AgO}$ which cannot be distinguished at the surface, however, according to XRD data discussed later, $\mathrm{Ag}^{0}$ prevails in the bulk phase. 


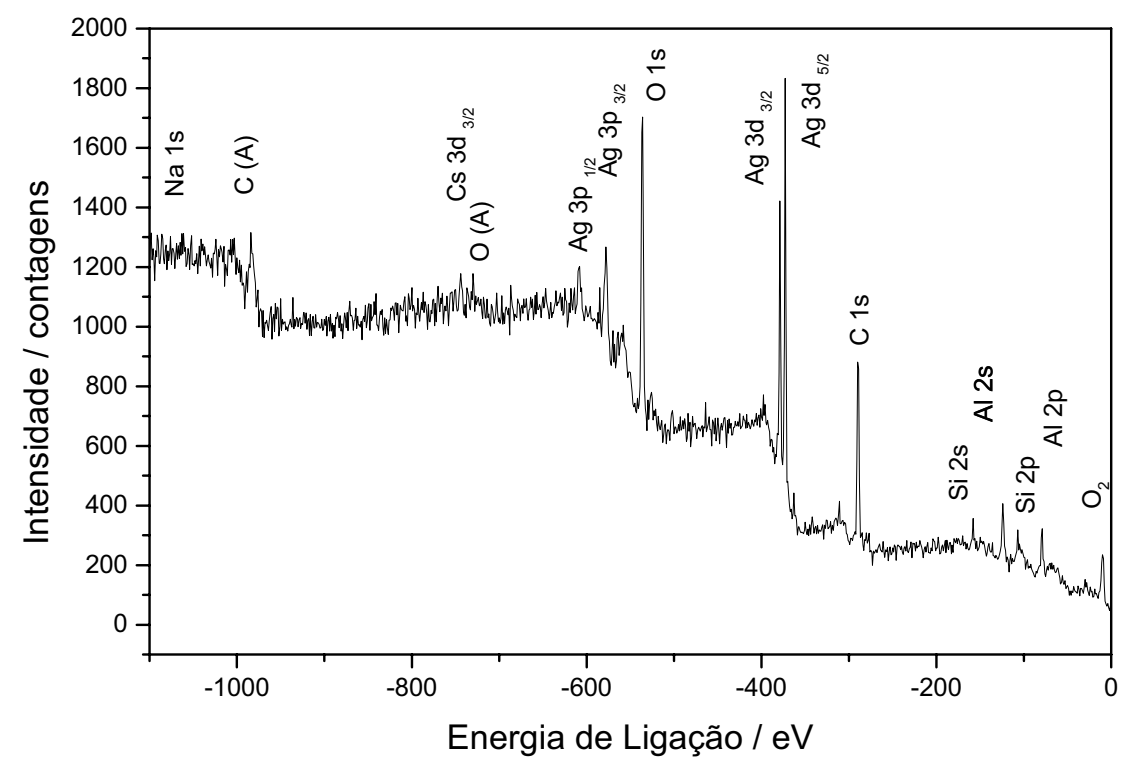

Fig. 1 - Cs, Ag/N catalyst XPS spectrum.

TABLE II

XPS surface atomic ratios.

\begin{tabular}{l|c|c|c|c|c|c}
\hline Catalyst & Ratio & Ratio & \multicolumn{2}{|c|}{ Ag/Al Atomic ratio } & \multicolumn{2}{c}{ Cs/Al Atomic ratio } \\
\hline & Si/Al & Na/Al & $\begin{array}{c}\text { Surface } \\
\text { (XPS) }\end{array}$ & $\begin{array}{c}\text { Bulk } \\
\text { (theoretical) }\end{array}$ & $\begin{array}{c}\text { Surface } \\
\text { (XPS) }\end{array}$ & $\begin{array}{c}\text { Bulk } \\
\text { (theoretical) }\end{array}$ \\
\hline $\mathrm{N}$ & 0.426 & - & & & & \\
\hline $\mathrm{Ag} / \mathrm{N}$ & 0.478 & 0.035 & 0.460 & 0.090 & - & - \\
\hline $\mathrm{Cs}, \mathrm{Ag} / \mathrm{N}$ & 0.507 & 0.005 & 0.394 & 0.085 & 0.018 & 0.0001 \\
\hline
\end{tabular}

TABLE III

XPS surface and bulk atomic ratios.

\begin{tabular}{l|c}
\hline Species & Ag 3d 5/2 Bond Energy (eV) \\
\hline $\mathrm{Ag} / \mathrm{N}$ & 367.8 \\
\hline $\mathrm{Cs}, \mathrm{Ag} / \mathrm{N}$ & 367.4 \\
\hline $\mathrm{Ag}^{0}$ & $367.6-368.2$ \\
\hline $\mathrm{AgO}$ & $366.9-368.1$ \\
\hline $\mathrm{Ag}_{2} \mathrm{O}$ & $367.2-368.0$ \\
\hline
\end{tabular}

\section{Scanning Electronic Microscopy (SEM)}

SEM images of the support and the silver catalysts are shown in Figures 3. The support shows uni- form roughness at the surface, with granular structure and two different sizes: small steps at the bottom $(0.5-2 \mu \mathrm{m})$ and greater steps emerging at the surface $(2-3.5 \mu \mathrm{m}) . \mathrm{Ag} / \mathrm{N}$ presents silver particles, well dispersed over the support, mainly present at the bottom plates, and with dimensions smaller than $0.5 \mu \mathrm{m}$. The $\mathrm{Cs}, \mathrm{Ag} / \mathrm{N}$ images revealed a much better dispersion of silver, when Cs was added to the silver catalyst. It also shows that silver particles occupy the entire support surface, including the major plates, not covered by silver alone, as observed in the previous case. Besides, the particle sizes were much smaller with Cs. These observations are in good agreement with the literature (Grant and Lambert 1985). 


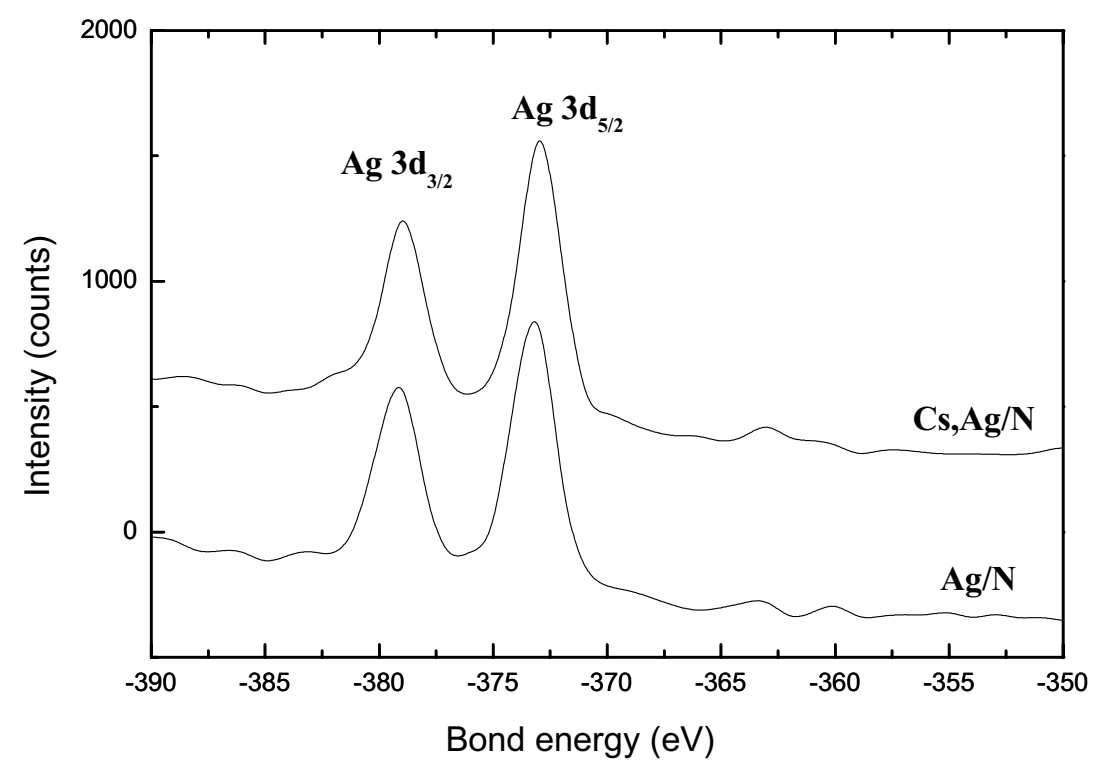

Fig. 2 - XPS spectrum of $\mathrm{Ag} 3 \mathrm{~d}$ band of the $\mathrm{Ag} / \mathrm{N}$ and $\mathrm{Cs}, \mathrm{Ag} / \mathrm{N}$ catalysts.

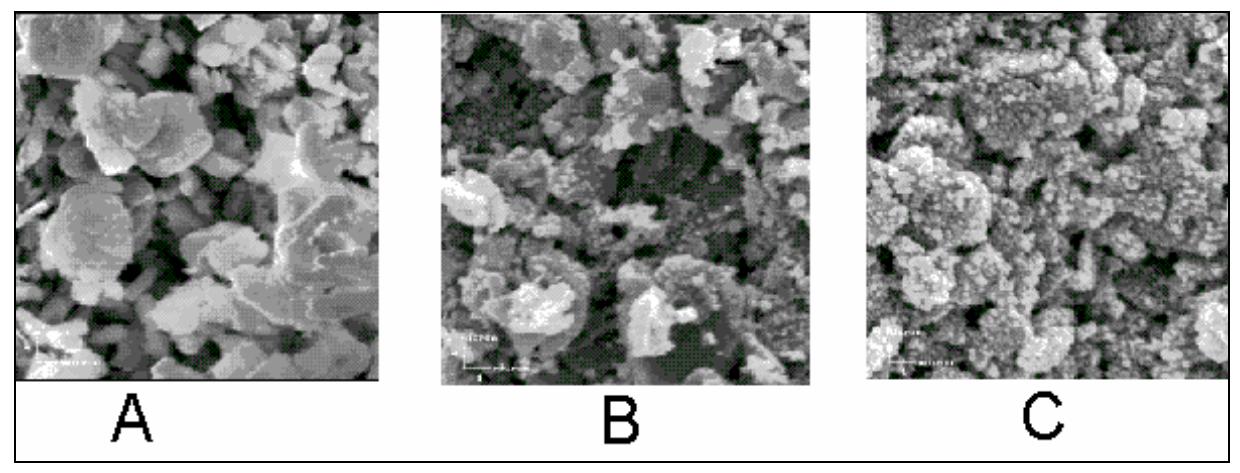

Fig. 3 - SEM image of (A) NORTON support, (B) Ag/N catalyst and (C) Cs,Ag/N catalyst (7500X).

\section{X-Ray DifFraction (XRD)}

The X-ray patterns of $\mathrm{Ag} / \mathrm{N}$ and $\mathrm{Cs}, \mathrm{Ag} / \mathrm{N}$ samples are displayed in Figure 4. Besides the peaks referred to $\alpha$-alumina support, peaks of metallic silver phase were also observed. With the Rietveld's refinement method it was possible to quantify this phase (Rietveld 1969): $15.2 \%$ and $15.5 \%$ for $\mathrm{Ag} / \mathrm{N}$ and $\mathrm{Cs}, \mathrm{Ag} / \mathrm{N}$ catalysts, respectively. These data are in accordance with the quantitative volumetric measurements, indicating that silver in its reduced state $\left(\mathrm{Ag}^{0}\right)$ is the prevailing phase. The crystallite average size was calculated, using Scherrer's equation
(Cullity 1959) (Table IV). The Ag/N and Cs, Ag/N catalysts presented coherent domain of silver average sizes (crystallites) similar to all reflections. This fact suggests that Cs did not alter silver crystallites average size for different presented crystalline faces, which was found to be between 40 and $60 \mathrm{~nm}$.

\section{Atomic Force Microscopy (AFM)}

AFM images are displayed in Figure 5, showing different topography and phase contrasts of the catalysts surfaces. The support showed regular topography with similar steps, as visualized on SEM analysis. The spaces between the steps are well defined 


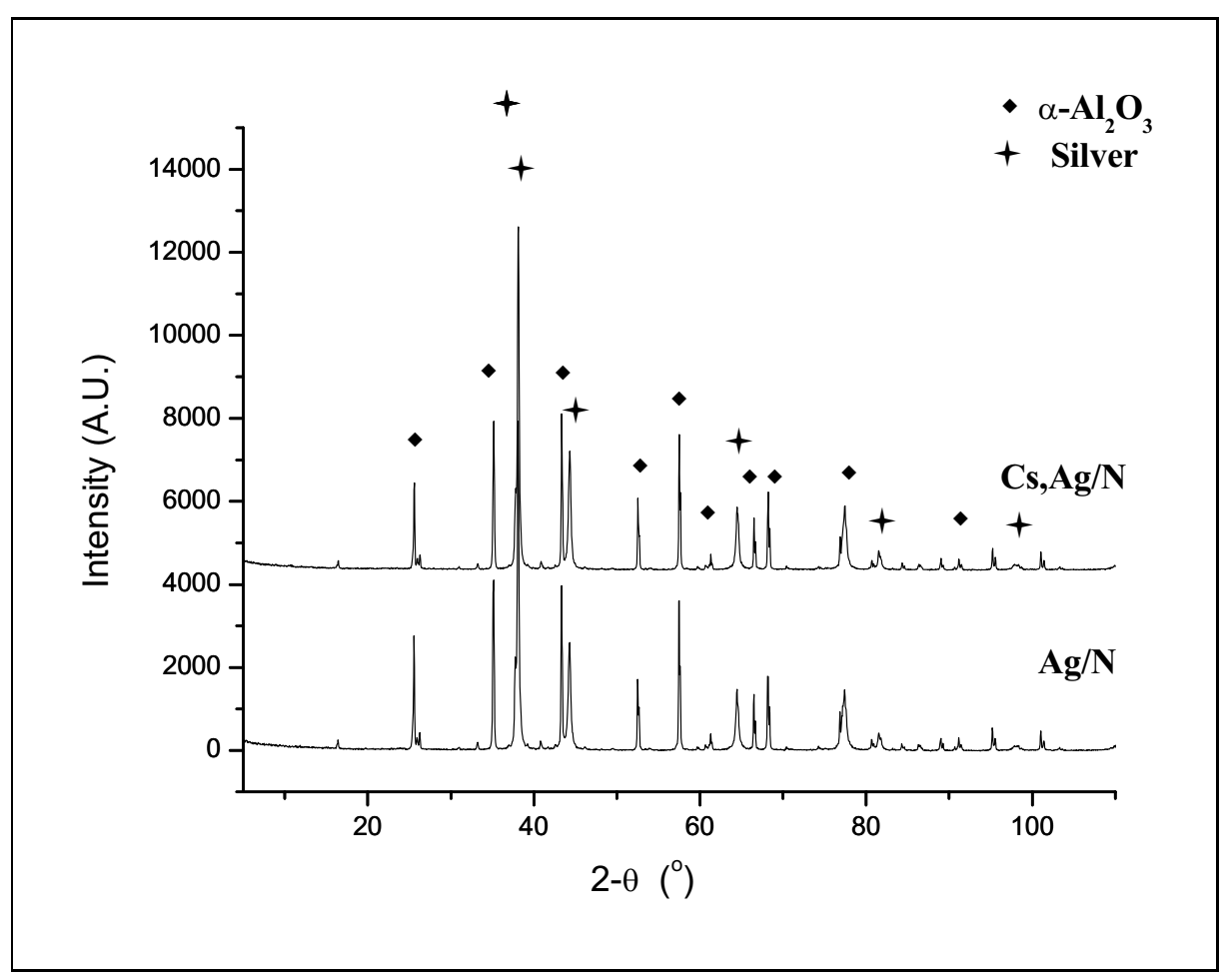

Fig. $4-\mathrm{Ag} / \mathrm{N}$ and $\mathrm{Cs}, \mathrm{Ag} / \mathrm{N}$ XRD diffractograms.

TABLE IV

XPS data of reference compounds obtained by literature (Wagner et al. 1979) and of $\mathrm{Ag} / \mathrm{N}$ and $\mathrm{Cs}, \mathrm{Ag} / \mathrm{N}$ catalysts experimentally obtained.

\begin{tabular}{l|c|c|c}
\hline Sample & \multicolumn{3}{|c}{ Diameter (nm) } \\
\hline & $(111)$ & $(200)$ & $(220)$ \\
\hline $\mathrm{Ag} / \mathrm{N}$ & 54.4 & 37.8 & 43.5 \\
\hline $\mathrm{Cs}, \mathrm{Ag} / \mathrm{N}$ & 57.9 & 39.4 & 43.0 \\
\hline
\end{tabular}

with dimensions of 500 and $1000 \mathrm{~nm}$. This sample did not present phase contrast, which indicates that alumina is uniform, with presence of only one compound. This result agrees with XRD analysis that presented $\alpha$-alumina predominantly. On the other hand, the $\mathrm{Ag} / \mathrm{N}$ catalyst showed uniform distribution of silver, mainly in the internal alumina steps, with regular particle size between 80 and 140 $\mathrm{nm}$. The phase contrast in this sample was well defined, showing the limits between silver parti- cles and the alumina support. The $\mathrm{Cs}, \mathrm{Ag} / \mathrm{N}$ catalyst images shows a homogeneous silver distribution, reaching all the support surface. The silver particle average size was estimated around 30 and $60 \mathrm{~nm}$. The contrast between the phases was not so clear as in the case of the $\mathrm{Ag} / \mathrm{N}$ sample, indicating the formation of a unique phase. The image suggests that a silver film covered the support and over this film, other silver particles are uniformly deposited. These silver particles are smaller than in the previous case of the $\mathrm{Ag} / \mathrm{N}$ sample. These results indicate that Cs promoted redistribution of silver over the $\alpha$-alumina surface, and therefore better dispersion of silver through generation of smaller Ag particle. The average silver particle size in the $\mathrm{Cs}, \mathrm{Ag} / \mathrm{N}$ catalyst is of the same order of Ag average crystallite size calculated by XRD. It suggests that $\mathrm{Cs}$ promoted the formation of silver very small particles of the order of a crystallite.

These data are in accordance with the results reported by literature (Epling et al. 1997, Minahan et 

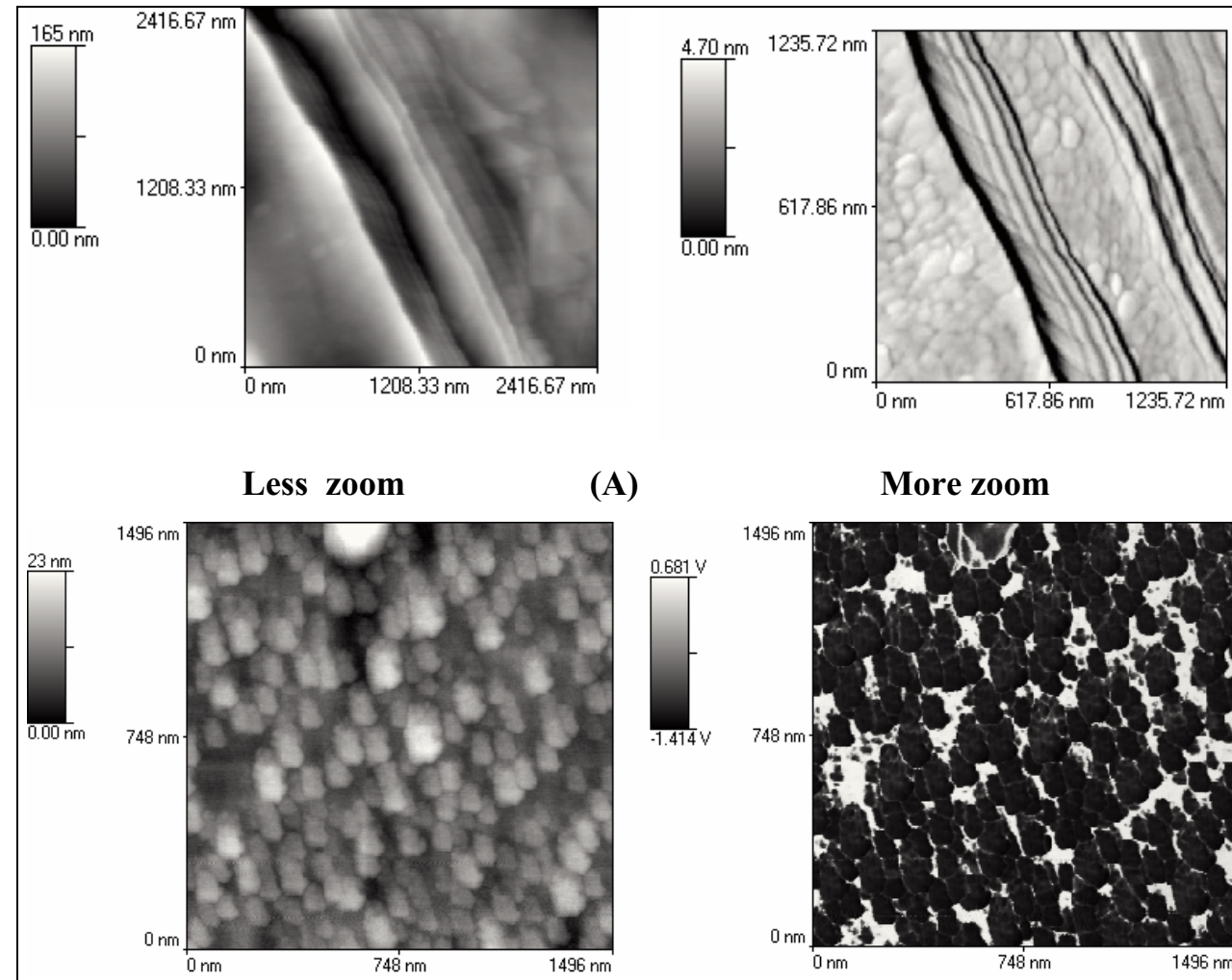

(A)
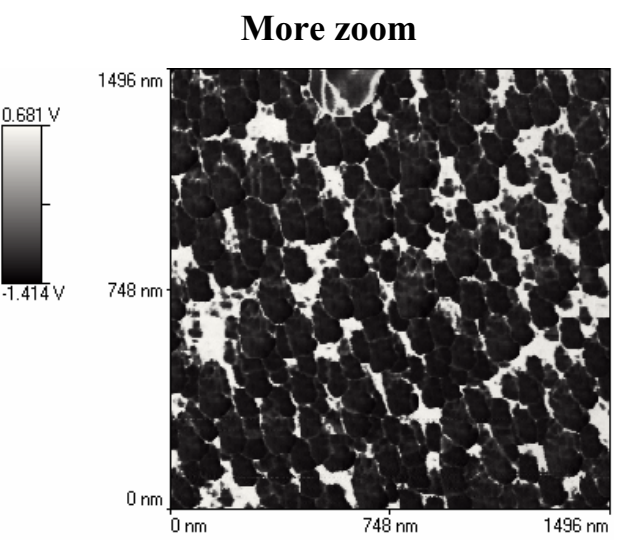

\section{Topography}

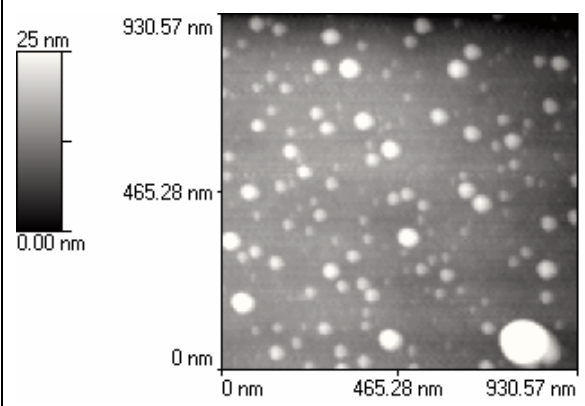

Topography
(B)

\section{Phase contrast}

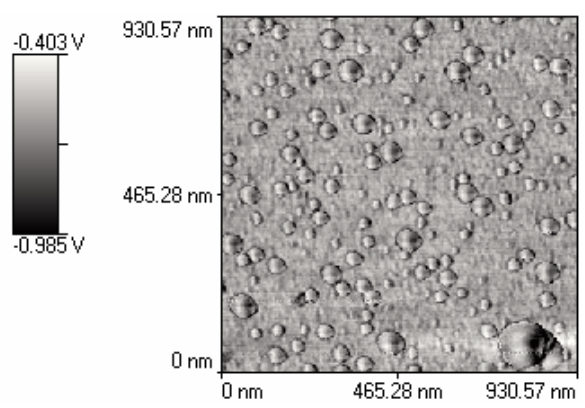

Phase contrast

Fig. 5 - AFM images: (A) support; (B) Ag/N and (C) $\mathrm{Cs}, \mathrm{Ag} / \mathrm{N}$.

al. 1997): SEM, ISS, AES and XPS results showed that silver catalysts present small bulk states, while on $\mathrm{Ag} / \mathrm{Cs}$ promoted catalyst (420 ppm of $\mathrm{Cs}$ ) the silver film covered most of the $\alpha-\mathrm{Al}_{2} \mathrm{O}_{3}$ surface. A small amount of cesium was observed, located at the surface, while the majority of the Cs was located between the silver film and $\alpha-\mathrm{Al}_{2} \mathrm{O}_{3}$ surface.
Therefore, they concluded that Cs acts like bonding between silver and the support and probably it affects the $\mathrm{Ag} / \mathrm{Al}_{2} \mathrm{O}_{3}$ electronic structure.

The formation of silver film at the $\mathrm{Cs}, \mathrm{Ag} / \mathrm{N}$ surface was not evidenced through XPS measurements. It does not show more silver enrichment at the surface, when compared to the non-promoted 
catalyst. However, XPS technique penetration surface sensibility is of the order of $30 \AA$, and probably a great fraction of the support can contribute to photoelectron current. The absence of silver surface enrichment on the cesium promoted sample does not contradict AFM results, and can be explained by the formation of a reasonable thin film with thickness of the order of a monolayer. The silver film formation, as indicated by phase contrast absence at AFM images of promoted catalyst, was also observed through ion scattering spectroscopy (ISS), which analyses the first atomic layer (Epling et al. 1997, Minahan et al. 1997).

\section{Catalytic Tests}

The reaction was performed in a fixed bed reactor at atmospheric pressure and feed containing 20\% ethylene, $5 \%$ oxygen, $7 \% \mathrm{CO}_{2}$ balanced with $\mathrm{N}_{2}(\mathrm{v})$, with a space velocity of $4000 \mathrm{~h}^{-1}$. After 303 hours with time on stream and a reaction temperature of $264^{\circ} \mathrm{C}$, the conversion of ethylene reached $8 \%$, but the selectivity on ethylene oxide was $5.18 \%$ (carbon balance). With addition of $\mathrm{Cs}$ in the catalyst the selectivity increased to $6.7 \%$, which corresponds to an enhancement of $30 \%$ of ethylene oxide, due to the promotion of Cs. This enhancement is attributed to the formation of silver particles over silver patches, increasing the contact with the reactants, as observed on SEM pictures. This effect did not influence the activity, because for the same reaction time and temperature the conversion was similar, however, it affected the selectivity of ethylene oxide, which can be attributed also to an electronic effect (Grant and Lambert 1985, Tan et al. 1987).

\section{CONCLUSIONS}

SEM, XRD and AFM results showed the cesium promoted the silver dispersion on the $\mathrm{Ag} / \mathrm{a}$-alumina system, leading to the formation of small silver particles over a thin silver film initially present over the $\mathrm{Ag} / \alpha-\mathrm{Al}_{2} \mathrm{O}_{3}$ catalyst.

AFM results measurements are significant allowing to the observation of the formation of the thin film and the dispersion of Ag, which on the con- trary, XPS did not allow to conclude, but only indicates the undistinguishable presence of silver either as metallic or oxidation state at the surface. XRD results confirm predominantly metallic silver in the bulk phase.

The formation of silver particles over silver patches increased the selectivity of ethylene oxide at a constant temperature and at isoconversion, which can also be attributed to an electronic effect.

\section{ACKNOWLEDGMENTS}

Valéria Vicentini, Oxiteno S.A., for catalytic evaluations.

\section{RESUMO}

Foram preparados catalisadores de prata suportados em $\alpha$-alumina e caracterizados por técnicas de BET, SEM, XRD e AFM. Resultados mostraram que são técnicas poderosas para a determinação da textura, morfologia e propriedades superficiais. Mostrou-se que a adição de $\mathrm{Cs}$ ao catalisador de $\mathrm{Ag} / \mathrm{Al}_{2} \mathrm{O}_{3}$ aumentou a dispersão de prata com a formação de pequenas partículas de prata sobre um filme fino formado sobre o suporte alumina. É importante salientar que as medidas feitas por AFM foram significativas para observar o filme e a dispersão da Ag e, ao contrário, XPS não detectou, contudo isto permite concluir que a prata está presente indistintamente no estado metálico ou óxido sobre a superfície. Resultados de XRD confirmam a presença dominante de prata metálica.

Palavras-chave: prata, césio, catalisador, AFM, XPS.

\section{REFERENCES}

Bal’zhinimaev BS, Zaikovskit VI, Pinaeva LG, RoMANENKO AV AND IvANOV GV. 1998. Catalytic and structural properties of the ultradispersed silver powders prepared by electroexplosion technique: a comparison with conventional silver catalysts. Kin Cat 39: 714-719.

Brunauer S, Emmett PH and Teller E. 1938. Adsorption of gases in multimolecular layers. J Amer Chem Soc 60: 309-319.

Bukhtiyarov VI, Boronin AI and Savchenko VI. 1994. Stages in the Modification of a Silver Surface for Catalysis of the Partial Oxidation of Ethylene: I. Action of Oxygen. J Cat 150: 262-267. 
Campbell CT. 1986. Chlorine promoters in selective ethylene epoxidation over $\mathrm{Ag}(111)$ - A comparison with $\mathrm{Ag}(110)$. J Cat 99: 28-38.

Cullity BD. 1959. Elements of X-Ray Diffraction. Reading, Addison-Wesley Publishing Company, Inc.

Deng JF, Yang J, Zhang S and Yuan XH. 1992. Promoting effects of $\mathrm{Re}$ and $\mathrm{Cs}$ on silver in ethylene epoxidation. J Cat 138: 395-399.

Epling WS, Hoflund GB and Minahan DM. 1997. Study of Cs-promoted $\alpha$-alumina-supported silver ethylene-epoxidation catalysts. IV. Model Study. J Cat 171: 490-497.

Goncharova SN, Paukshtis EA AND BaL'zhinimaev BS. 1995. Size effect in ethylene oxidation on silver catalysts. Influence of support and Cs promoter. Appl Cat 126: 67-84.

Grant RB AND LAmbert RM. 1985. A single-crystal study of silver-catalyzed selective oxidation and total oxidation of ethylene. J Cat 92: 364-375.

Kobal Júnior J and Sartorio L. 1981. Manual de Análise Química Quantitativa Convencional. São Paulo, Ed. Moderna.

LiU Y AND Shen S. 1995. Direct epoxidation of ethylene in a dilute reaction stream in oxidative coupling of methane. Appl Cat A: Gen., 121: 57-68.

Minahan DM and Hoflund GB. 1996. Study of Cs-promoted, $\alpha$-alumina-supported silver ethyleneepoxidation catalysts. I. Characterization of the support and as-prepared catalyst. J Cat 158: 109-115.
Minahan DM, Hoflund GB, Epling WS and SchoenFELD D. 1997. Study of Cs-promoted, $\alpha$-aluminasupported silver ethylene-epoxidation catalysts. III. Characterization of Cs-promoted and nonpromoted catalysts. J Cat 168: 393-399.

Riassian M, Trimm PJ and Williams PM. 1977. Catalytic activity of supported silver for oxidation of ethylene - activity patters on different supports. J Cat 46: 82-90.

Rietveld HM. 1969. A profile refinement method for nuclear and magnetic structures. J Appl Cryst 2: 65 , part 2.

Serafin JG, Liu AC and Seyedmonir SR. 1998. Surface science and the silver-catalyzed epoxidation of ethylene: an industrial perspective. J Cat 131: 157-168.

TAN SA, GRANT RB AND LAMbert RM. 1987. The silver catalyzed decomposition of $\mathrm{N}_{2} \mathrm{O}$ over $\mathrm{Ag}(111)$ and $\mathrm{Ag} / \alpha-\mathrm{Al}_{2} \mathrm{O}_{3}$. J Cat 104: 156-163.

VAn SANTEn RA AND KuIPERS HPCE. 1987. The mechanism of ethylene epoxidation. Adv Cat 35: 265-321.

Wagner C, Riggs WM, Davis LE, Moulder JF AND Muilenberg GE. 1979. Handbook of X-Ray Photoelectron Spectroscopy. Minnesota, Perkin Elmer Coorp.

Young VWY, Hoflund GB And Miller AC. 1990. A model for analysis and quantification of ion scattering spectroscopy data. Surf Sci 235: 60-66. 